\title{
The Role of PDGF Gene in Tissue Regeneration of Digit Tip Mice (Mus musculus)
}

\author{
Titta Novianti ${ }^{1}$ Tazkia Ayu Safitri ${ }^{1}$ Febriana Dwi Wahyuni ${ }^{1}$ It Jamilah ${ }^{2}$ \\ Syafruddin Ilyas ${ }^{2 *}$ \\ ${ }^{I}$ Dept. of Biotechnology, Faculty of Health Sciences (FIKES, Universitas Esa Unggul, Jakarta, Indonesia \\ ${ }^{2}$ Dept. of Biology, Faculty of Mathematics and Science (FMIPA), Universitas Sumatera Utara, Medan \\ *Corresponding author. Email:Syaruddin@usu.ac.id
}

\begin{abstract}
Some genes play a role in the tissue regeneration process and they have specific functions. One of them is the platelet-derived growth factors (PDGF) gene that have a role in the wound healing process because it induces cell mitosis and thereby causes cell proliferation. PDGF protein expression is thought to chemotactically recruit many cell types including smooth muscle, fibroblasts, and monocytes to migrate to the wound site. These research aims are to analyze the role of PDGF gene expression in the process of digit tip mice tissue regeneration. This study used 24 mice (Mus musculus) were amputated at the digit tip and the growth was observed on days $0,1,3,5,10,15$, and 25 . We isolated RNA from each tissue after amputation on days $0,1,3$, $5,10,15$, and 25 and analyzed the RNA expression of the PDGF gene using the qPCR method. PDGF gene expression reached its peak on day 10 on the granule phase and decreased until day 25 . The peak expression of the PDGF gene indicates the role of the gene in the tissue regeneration of digit tip mice. The normality test for PDGF gene expression was normally distributed $(p>0,05)$ and the variation test between each treatment was different significantly $(\mathrm{p}<0.05)$.
\end{abstract}

Keywords: PDGF, tissue regeneration, mice, granule phase, amputated

\section{INTRODUCTION}

Regeneration of tissue is not a simple process and an interesting issue (1). Regeneration of tissue has four stages process. Each stage has a function in the regeneration of tissue. Wound-healing is the first phase that has a role in overcoming wounds in the tissue. The granular stage is the second stage which plays a role in forming various new tissue-forming stem cells. In the third stage, the regeneration stage, a new tissue formation process occurs. The last stage of the regeneration of tissue is the maturation stage. The new tissue that is formed undergoes maturation and morphogenesis process (2).

The tissue regeneration process needs some molecules, genes, and proteins that have a function in tissue regeneration (3). Granulation is characterized by the fibroblasts and endothelial cells proliferated and new epithelial layers formatted. Fibroblasts have a role stimulate the formation of an extracellular matrix. The rest of the extracellular matrix is cleaned by the macrophage cells to balance between extracellular matrix production and extracellular degradation. This stage makes the tissue formation occurs simultaneously with the tissue maturation stage (4).

Some researchers reported that several genes have specific functions in the tissue regeneration process. One of them is the platelet-derived growth factor (PDGF) gene which has a role in wound healing (5). The PDGF gene initiates an inflammatory response and modulates endothelial cells indirectly in angiogenesis. PDGF has a specific function in the formation and expansion of fibroblasts derived from the microvascular pericyte. PDGF has amino acids that are involved in the formation of the ECM extracellular matrix. PDGF acts as a mitogen and activator of HSC that can produce ECM. PDGF has an important role in the strongest mitogen of mesenchymal cells because it is a strong 
inducer of extracellular matrix components by mesenchymal cells (6)

The hypothesis that the PDGF gene has a role in the regeneration of digit tip mice tissue. We analyze the gene expression of the PDGF gene by the qPCR method in the regeneration of digit tip mice tissue after amputation.

\section{MATERIALS AND METHODS}

\subsection{Research sample}

A research code of ethics was obtained from the Commission Research of Ethics in Universitas Esa Unggul. The sample of this research sample was 30 female mice (Mus musculus) var Swiss Webstar, aged 8 weeks and weight 20 grams. The number of samples using the Federer formula. Mice were obtained from the Ministry of Health of the Republic of Indonesia, kept and treated the mice in the laboratory of the Ministry of Health of the Republic of Indonesia.

We euthanized the mice with ketamine/xylazine at a dose of $0.5 \mathrm{~g} / \mathrm{kg} \mathrm{BW}$. After euthanized the mice, we amputated the digit tips mice. We isolated the regeneration of tissue growth on day 0 (4 hours after amputation), 1, 3, 5, 10, 15, and day 25 after amputation to analyze the gene expression by the qPCR method.

\subsection{RNA isolation from tissue regenerated}

In the regenerated tissue, the samples of digit tip mice were weighed. The weight of the sample became the standard volume for the required Tri-pure RNA isolation kit. We incubated the samples at room temperature $15-30{ }^{\circ} \mathrm{C}$ for 5 minutes and added chloroform according to the conversion of the sample weight. We incubated the samples at $30{ }^{\circ} \mathrm{C}$ for 15 minutes. Samples were centrifuged at a rate of 12.000 $\mathrm{x} g$ for 15 minutes at $4{ }^{\circ} \mathrm{C}$. We separated the aqueous phase and added $500 \mu \mathrm{l}$ of isopropyl alcohol, then incubated at $15-30{ }^{\circ} \mathrm{C}$ for 10 minutes. We centrifuged the sample, removed the supernatant, added $10 \mu \mathrm{l}$ of DEPC treated water to each sample, and incubated at $55-6^{\circ} \mathrm{C}$. The RNA isolation samples were analyzed by qPCR to analyze the gene expression.
The primary design of the PDGF gene of mice (Mus musculus). The primary design results are obtained as follows:

\section{Left Primer: CCTTCTCCAGTGTGCTGACA Right Primer: GGAGTCCATAGGGAGGAAGC}

Product Size PCR: 158 bp and annealing temperature: $55{ }^{\circ} \mathrm{C}-60{ }^{\circ} \mathrm{C}$

\section{RESULT AND DISCUSSION}

\subsection{Growth length of the digit tip Mice}

Figure 1. showed the growth of digit tip mice. The data distribution of tissue regeneration growth of digit tip mice was normal ( $p>0.05$ ). The growth length showed increased slowly from day 0 until day 10 , in this phase some of the stem cells do division and differentiation. The first 10 days is the stage of wound healing, the growth is very slow. This is the inflammation and granulation phase process of stem cells, like mesenchymal (7). There is no tissue differentiation and the growth length of tissue. So that in both phases there is no tissue growth and no significant tissue growth (4).

At the wound healing stage, some cells do the proliferation, differentiation, and migration cell. This process impacts a little of the digit tip mice growth. Mescher reported that at the wound-healing phase, the tissue was characterized by migration, proliferation, and differentiation of cells. They are the macrophage cells, fibroblasts, and progenitor cells (1).

In zebrafish tissue regeneration, it has been investigated the existence of cell migration at the wound healing stage from various organs. Tahara reported that in the heart tissue regeneration process of zebrafish, the cardiomyocytes and the cardiac progenitor cells migration to the heart tube. (8). Some leukocytes, fibroblast-like cells, basal lamina cells, nerve cells, cartilage cells, and muscle cells were found at the wound healing phase in tail regeneration of lizards. The various tissues proliferated and differentiated actively (3). 


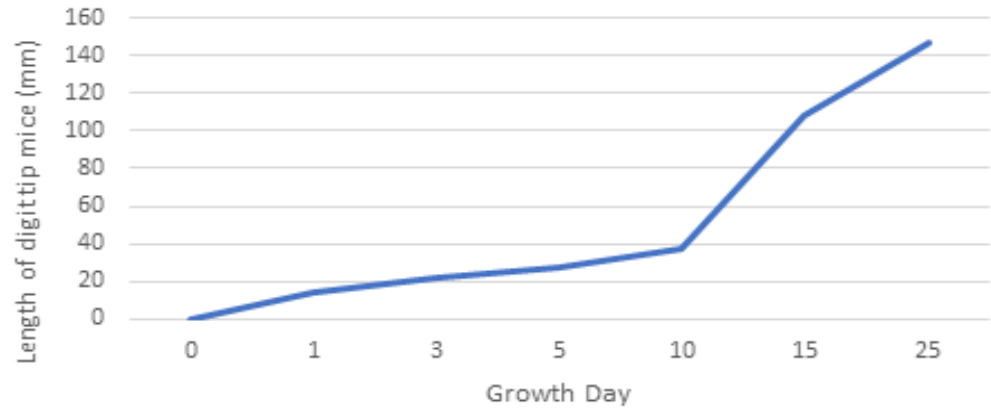

Figure 1. The growth of tissue regeneration of digit tip mice from day 0 until day 25 after amputation. The line graph showed an increase significantly from day 10 until day 25.

After day 10, the graph of tissue growth length digit tip mice increased significantly. It occurred the formation of new connective tissue, nerve tissue, muscle tissue, dermis tissue, bone tissue, and nail tissue, resulting in a significant increase in tissue length. Hutchin reported that the regeneration of green lizard tails started on day 10-15, he found the aggregates cell of stem cells (9).

The tissue regenerates actively to form elongated bone tissue, new muscle formation, new blood vessels, and new fatty tissue. The tissue grew from the aggregate of stem cells in the dermis layer (10). After day 10 the tissue grs in the regeneration phase followed by a tissue maturation phase after day 20 .

The growth of digit tip mice was different significantly between day 10 and day 25 because in this phase the tissues are morphogenesis and differentiation. At this time, the tissue has been covered by a sufficient layer of the thick epidermis.

In the regeneration of human skin organs, there are several phases of regeneration, namely the wound healing phase which includes inflammation in the form of a lag phase growth curve, followed by the proliferation and regeneration phases which include wound closure, angiogenesis, and granulation or proliferation, and finally, the remodeling phase starting on day 12 (11) .

The results of the qPCR amplification showed a specific expression of the PDGF gene, it was seen that a melt curve image had one peak (Figure 2). The amplification results showed a specific amplification of the PDGF and 18S genes as positive controls (Figure 3). That showed that the DNA primer design is specific for the PDGF gene of mice.

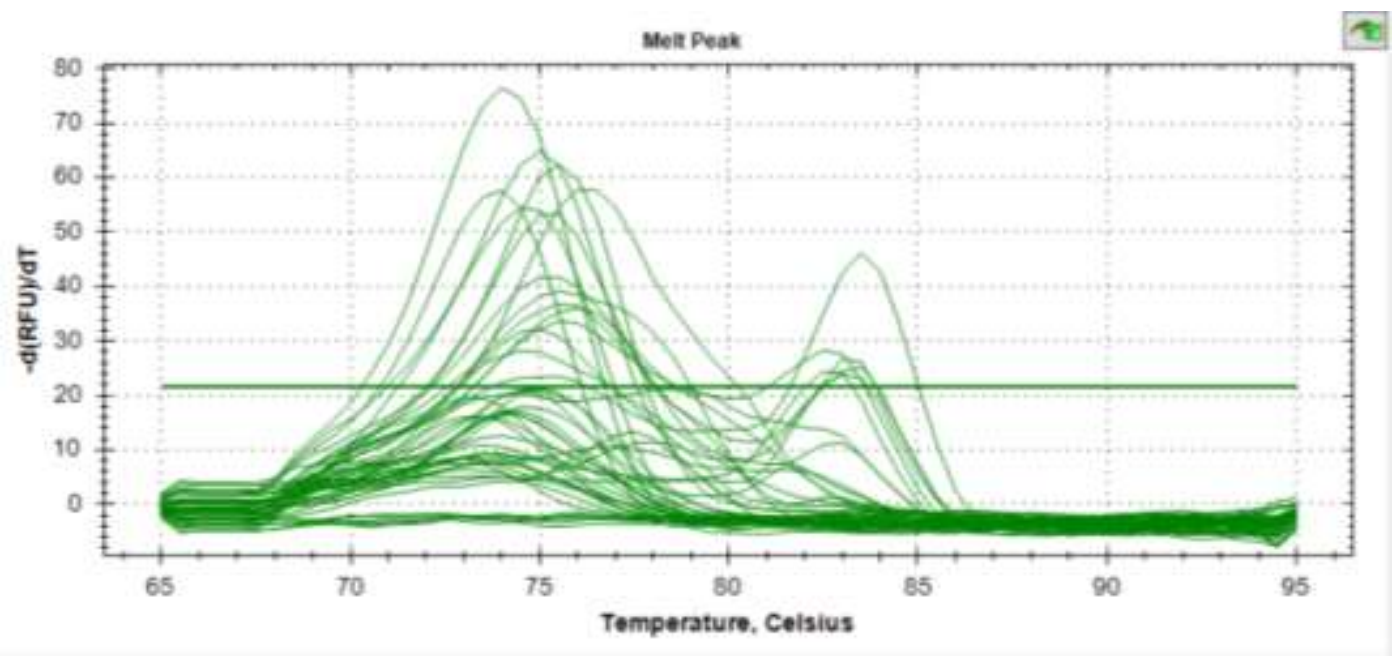

Figure 2. Melting Curve of PDGF and 18S genes 


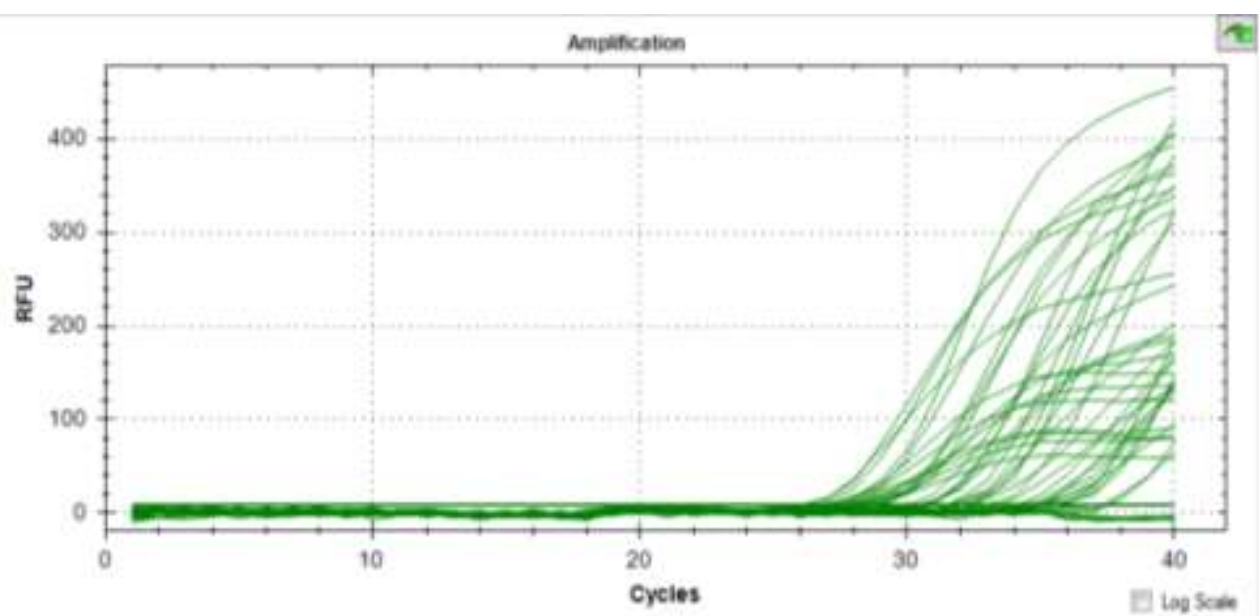

Figure 3. PDGF and $18 \mathrm{~S}$ genes amplification results

\section{2. mRNA of PDGF gene expression relative to controls}

PDGF gene expression is depicted in the following graph in Figure 4 below. We used the $18 \mathrm{~S}$ gene as a positive control that had a role as a housekeeping gene. We used the digit tip of mice that were not treated with amputation as the negative control.

The beginning of PDGF gene expression increased after day 1. The expression was still increased until day 10 and reached the peak on day 10. The gene expression was decreased significantly after day 10 until day 25, but the expression was still higher than the control expression. It showed that the gene expression was still high during the tissue regeneration process. We suggested that the gene had a role in the tissue regeneration process. The high expression of the PDGF gene in the inflammatory phase showed that the gene had a role in initiate of inflammatory response. In the granular phase, the expression of the PDGF gene was high which is related to the role in vessel blood formatted (5).

PDGF stimulated the formation of extracellular matrix in the fibroblast cell in the regeneration phase after granulation. The amino acids of PDGF are involved in the formation of the ECM extracellular matrix. The expression of the PDGF gene was highest in the phase during the tissue regeneration process (6).

After day 10, the expression of the PDGF gene decreased but it still higher expression than control. It showed that in this phase the PDGF had a role in proliferated and migrated cells for the formation of new tissue. In this phase, the tissue extended growth significantly which was the beginning of cartilage growth. The blastema cells of cartilage differentiated and migrated to form the cartilage tissue. The cartilage grew fastly after day 21 . In this phase, the muscle tissue, nerve tissue, blood vessel, and adipose tissues grew fast too.

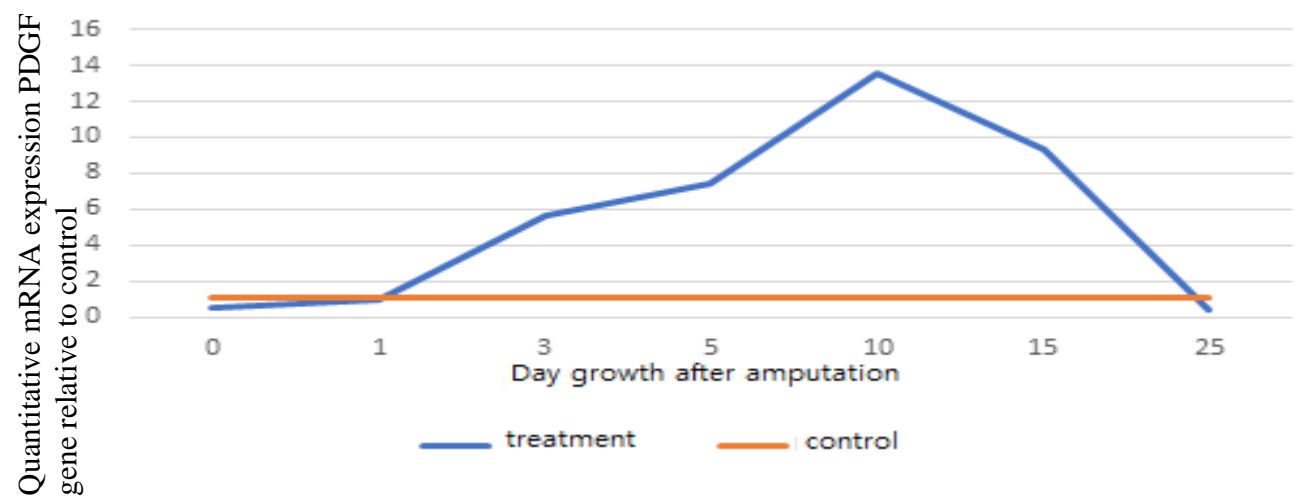

Figure 4. Graph of PDGF gene mRNA expression relative to control after amputation from day 0 until day 25 
After day 15, the gene expression continued to decline even on day 25 the quantitative amount of PDGF gene mRNA expression was less than the control, this indicated that the PDGF gene did not have a role at all in this phase. Because the phase after day 25 in tissue regeneration is the maturation of tissue. The tissue undergoes the morphogenesis process to form the adult tissue. Then the tissue regeneration process has been completed.

The results of the data normality test for the quantity of PDGF gene mRNA expression relative to the control from day 0 to day 25 , the distribution was normal ( $p>0.05)$. Meanwhile, the data homogeneity test showed a heterogeneous distribution of data from day 0 to day $25(\mathrm{p}<.05)$.

\section{CONCLUSION}

The PDGF gene has a role in the tissue regeneration process to regulate the proliferation, migration, and formation of new endothelial cells, it was showed the high expression of the gene.

\section{AUTHORS' CONTRIBUTION}

All authors contributed to this study. TN contributed to research ideas and wrote articles, TAS and FDW contributed to research in the laboratory, IJ and SI were in charge of analyzing research data.

\section{ACKNOWLEDGMENT}

Thank you to the Ministry of Education and Culture DIKTI for the research grant -PKPT, thanks to Esa Unggul University who has supported this research a lot, we would also like to thank the University of North Sumatra for being willing to be a research partner and finally, a big thank you to Dr. Aroem Naroeni, Ph.D. who has helped a lot in conducting research.

\section{REFERENCES}

[1] A.L. Mescher, Macrophages and fibroblasts during inflammation and tissue repair in models of organ regeneration, Willey Regeneration, vol 4, 207, pp. 39-53.

[2] W.A. Fernando, E. Leininger, J. Simkin, N. Li, C.A. Malcom, S. Sathyamoorthi, M. Han, K. Muneoka, Wound healing and blastema formation in regenerating digit tips of adult mice. Developmental Biology, vol. 350, 2011, pp. 301-310.

[3] T. Novianti, V. Juniantito, A.A. Jusuf, E.A. Arida, M. Sadikin, S.W.A. Jusman, High expressions of the cytoglobin and PGC-1 $\alpha$ genes during the tissue regeneration of house gecko (Hemidactylus platyurus) tails, BMC Developmental Biology 202020.

[4] T.A. Wynn, K.M. Vannella, Macrophages in Tissue Repair, Regeneration, and Fibrosis. Immunity 44 (2016) 450-462.

[5] P. Rishikaysh, K. Dev, D. Diaz, W.M.S Qureshi, S. Filip, J. Mokry, Signaling involved in hair follicle morphogenesis and development. International Journal of Molecular Sciences 15 (2014) 1647-1670.

[6] F. Ng, S. Boucher, S. Koh, K.S.R. Sastry, L. Chase, U. Lakshmipathy, C. Choong, Z. Yang, M.C. Vemuri, M.S. Rao, V. Tanavde. PDGF, TGF- 2. and FGF signaling is important for differentiation and growth of mesenchymal stem cells (MSC): Transcriptional profiling can identify markers and signaling pathways important in differentiation of MSCs into adipogenic, chondrogenic, and osteogenic lineages, Blood 112 (2008) 295-307.

[7] N. Vitulo, D.L. Valle, T. Skobo, G. Valle, L. Alibardi, Transcriptome analysis of the regenerating tail vs. the scarring limb in lizard reveals pathways leading to successful vs. unsuccessful organ regeneration in amniotes, Developmental Dynamics 246 (2017)116-134.

[8] N. Tahara, M. Brush, Y. Kawakami, Cell migration during heart regeneration in Zebrafish, Dev Dyn 247 (2016) 7744-787.

[9] E.D. Hutchins, G.J. Markov, W.L. Eckalbar, R.M. George, J.M. King, M.A. Tokuyama, L.A. Geiger, N. Emmert, M.J. Ammar, A.N. Allen, A.L. Siniard, J.J. Corneveaux, R.E. Fisher, J. Wade, D.F. DeNardo, J.A. Rawls, M.J. Huentelman, J. Wilson-Rawls, K. Kusumi, Transcriptomic analysis of tail regeneration in the lizard Anolis carolinensis reveals activation of conserved vertebrate developmental and repair mechanisms, PLOS ONE 9(8) (2014).

[10] R.E. Fisher, L.A. Geiger, L.K. Stroik, E.D. Hutchins, R.M. George, D.F. Denardo, K. Kusumi, J.A. Rawls, J. Wilson-Rawls A 
Histological Comparison of the Original and Regenerated Tail in the Green Anole, Anolis carolinensis, The Anatomical Record: Advances in Integrative Anatomy and Evolutionary Biology 295 (2012) 1609-1619.

[11] A. Akhmetshina, K. Palumbo, C. Dees, C. Bergmann, P. Venalis, P. Zerr, A. Horn, T.
Kireva, C. Beyer, J. Zwerina, H. Schneider, A. Sadowski, M.O. Riener, O.A. MacDougald, O. Distler, G. Schett, J.H.W. Distler, Activation of canonical Wnt signalling is required for TGF- $\beta$ mediated fibrosis, Nature Communications 3 (2012) 17-34 